\title{
O DUPLO VISCONDE PARTIDO AO MEIO DE ITALO CALVINO
}

\author{
The double cloven viscount by Italo Calvino
}

\author{
Natalia Guerra Brisola Gomes* \\ Luciana Brito**
}

\begin{abstract}
RESUMO
Ainda que com personagens e enredos isolados, os romances da trilogia I nostri antenati, de Italo Calvino, dialogam entre si pela questão da busca do indivíduo por uma identidade própria. A primeira história, $O$ visconde partido ao meio, trata o assunto a partir da alteridade, ilustrando que o conhecer-se a si mesmo depende também de uma visão externa, a interpretação de outro ser. Medardo di Terralba, um visconde nada afeito a questionamentos e reflexões, de repente tem seu corpo divido em dois durante uma batalha. Ao se transformar em metades física e mentalmente independentes, o jovem compreende sua incompletude. A partir de então, detentor de um duplo, o protagonista passa por diversas situações semelhantes às dos clássicos da literatura e da psicologia que se debruçam sobre essa temática. A narrativa do escritor italiano permite, portanto, uma considerável apreciação de variadas apresentações do tema ao longo dos séculos.
\end{abstract}

Palavras-chave: alteridade; $O$ visconde partido ao meio; Italo Calvino.

\begin{abstract}
Even with isolated characters and plots, the novels of the $I$ nostri antenati trilogy, by Italo Calvino, interact with each other by the subject of the individual quest for a self-identity. The first story, The cloven viscount, treats the subject from the perspective of alterity, illustrating that knowing yourself also depends on an external view, on another being's interpreta-

* UEL - Universidade Estadual de Londrina

** UENP - Universidade Estadual do Norte do Paraná
\end{abstract}


tion. Medardo di Terralba, a viscount not wont to questions and reflections, suddenly has his body split in two during a battle. As he becomes two physically and mentally independent halves, the young man understands his incompleteness. Since then, having a double, the protagonist gets through various situations similar to those of the classics of psychology and literature that focus on this theme. The Italian writer's narrative, therefore, allows a considerable appreciation of different presentations of the subject over the centuries.

Keywords: alterity; The cloven viscount, Italo Calvino.

\section{INTRODUÇÃo}

O lugar de Italo Calvino entre os maiores literatos italianos do século passado se deve, em parte, pelo envolvimento de seu trabalho com o insólito. Enquanto editor, se empenhou numa profunda pesquisa sobre as fábulas, registradas ou não, de seu país (Fiabe Italiane, 1956), além de ter organizado uma coletânea de contos fantásticos do século XIX (Racconti fantastici dell'Ottocento, 1983). Ainda mais comprometida com esse ramo da literatura foi sua produção autoral, desde os primeiros textos, nos anos de 1940. Na década seguinte, tal característica seria consolidada por meio da trilogia I nostri antenati, que partia do cenário mítico da Idade Média para criar enredos e personagens inusitados. Assim surgiram as histórias de um visconde bipartido física e mentalmente (Il visconte dimezzato, 1952), de um jovem decidido a viver somente em cima das árvores (Il barone rampante, 1957) e de um cavaleiro inexistente, que habitava numa armadura oca (Il cavaliere inesistente, 1959).

Temos como objetivo, no presente trabalho, analisar a maneira como Calvino fez uso do insólito em Il visconte dimezzato, caracterizado pelo tema do duplo. No livro, traduzido no Brasil como $O$ visconde partido ao meio, Medardo di Terralba participava de uma guerra contra os turcos quando foi atingido no peito por uma bala de canhão. Os médicos do exército conseguiram recuperar apenas sua metade esquerda, que regressou para casa e logo demonstrou aos conterrâneos concentrar em si apenas os sentimentos negativos do ser completo que outrora fora. Após Terralba passar anos sob o reinado do maldoso meio-visconde, surgiu nos arredores sua parte esquerda, encontrada e tratada por eremitas no deserto. Para surpresa de todos, essa metade possuía todos os atributos positivos do antigo Medardo e dedicava sua vida a ajudar pessoas e distribuir bons conselhos. Entretanto, graças ao excessivo moralismo e à abnegação extrema, não demorou muito para que a companhia de O Bom se revelasse tão indesejada quanto a de O Mesquinho. Ficou, assim, comprovado que a paz seria recuperada apenas quando ambas as partes fossem novamente unidas. 


\section{As metades DE UM VISCONDE}

Desde a Antiguidade clássica, gêmeos, sósias, sombras, reflexos e outros ícones correspondentes à imagem do indivíduo figuraram o duplo nas artes. Ora gerando riso pelas diversas confusões motivadas, ora causando temor e desconforto aos que viam nisso um presságio de usurpação de identidade, a questão sempre esteve relacionada ao rompimento dos limites humanos. Ao se descobrir duplicado, cada original pode reagir de uma maneira, seja encontrando vantagens em possíveis inversões de papéis, seja negando sua cópia e, assim, evitando lidar com os próprios defeitos e fraquezas por ela evidenciados. Há ainda personagens que são tomados pelo ciúme de dividir seu contexto com um semelhante e os que se amarguram com a dúvida de serem a personalidade dominante, a matriz da duplicação, ou de não passarem de mera cópia de seu duplo, sentimento sobre o qual pondera Clément Rosset (2008, p. 88): "No par maléfico que une o eu a um outro fantasmático, o real não está do lado do eu, mas sim do lado do fantasma: não é o outro que me duplica, sou eu que sou o duplo do outro. Para ele o real, para mim a sombra".

No caso de Medardo, a peculiar situação em que se encontrava, dividido em duas metades de consciência e vontade independentes, se transformou em um processo de autoconhecimento, visto que cada uma de suas personalidades pôde observar a outra sob uma perspectiva externa, afastada e, portanto, ampliada. Nisso $O$ visconde partido ao meio se diferencia dos principais textos sobre o duplo, pois nenhum dos meio-viscondes deseja aniquilar seu par, uma vez que ambos surgiram de uma mesma matriz, numa mesma ocasião. Não há neles sentimento de inferioridade ou ameaça, pois são igualmente realidade e sombra, carregando em si parte do personagem em seu estado original. Em contrapartida, também não se deve concluir que tal falta de rivalidade se explique por meio do narcisismo, sendo eles admiradores da própria imagem que se reflete no semelhante. É ausente em ambos qualquer desejo de aproximação e parceria com o duplo, seja pela curiosidade ou pelo intuito de enganar as demais pessoas. Os dois se mantêm indiferentes, embora conscientes de suas mútuas existências.

Podemos entender essa falta de interesse das metades por suas imagens duplas como uma esquiva ao reconhecimento das contradições presentes no interior de Medardo. Enquanto não se colocam uma em frente à outra, não precisam encarar o fato de serem parte de uma mesma personagem, de temperamentos conflitantes. De fato, O Bom e O Mesquinho adiaram o encontro até o décimo e último capítulo do livro, quando o embate se mostrou inevitável, e, ainda assim, não se deveu à iniciativa deles, mas à artimanha de Pamela. A moça, alvo do amor dos dois meio-viscondes, ao 
mesmo tempo insatisfeita com seus incompletos pretendentes e atraída por eles, não pôde escolher apenas um noivo e aceitou se casar com ambos na mesma ocasião. Para solucionar o conflito, foi proposto um duelo entre as metades, que atingiram uma à outra na exata linha que antes as dividiu. $O$ ferimento de guerra reaberto possibilitou que um médico de Terralba ligasse novamente as partes e restabelecesse um único e completo Medardo.

o processo de amadurecimento do personagem se dá, porém, muito antes da intervenção cirúrgica do dr. Trelawney. No início do enredo, nos deparamos com um jovem Medardo impulsivo e repleto de certezas, numa "idade em que os sentimentos se misturam todos num ímpeto confuso, ainda não separados em bem e mal; a idade em que cada experiência nova, também macabra e desumana, é toda trepidante e efervescente de amor pela vida." (CALVINO, 2011, p. 11-12). Estar nessa primeira juventude, tão seguro de si, foi justamente a razão de Medardo acabar por se dividir em dois: sua inexperiência em batalhas o fez cometer o crasso erro de atacar um canhão de frente, sendo atingido em cheio por uma bala.

Dividido ao meio, o visconde tomou consciência de sua incompletude e se tornou mais humilde e sábio. Não apenas O Bom, com seu otimismo, reconhecia os benefícios ocasionados pelo ferimento, mas também a parte má de Medardo, cujo desejo era de "que todos pudessem sair de sua obtusa e ignorante inteireza. Estava inteiro e para mim as coisas eram naturais e confusas, estúpidas como o ar: acreditava ver tudo e só havia a casca." (CALVINO, 2011, p. 50). Enquanto O Mesquinho resolvia dar seu próprio jeito no mundo, partindo em dois, fisicamente, tudo que encontrava na natureza, a metade bondosa entendia que, subjetivamente, todas as pessoas eram divididas como ele; bastava perceberem sua real condição para compreenderem melhor umas às outras e se tornarem sensíveis a "todas as mutilações e as faltas do mundo" (CALVINO, 2011, p. 70-71). Se, antes, os meio-viscondes viam uma completa cisão entre o eu e o outro, este representando tudo que é externo e diferente, o fato de se tornarem homens partidos fez com que repensassem sua relação com a sociedade. Nela, agora, se encontrava o duplo de cada um, sendo que apenas no outro encontrariam sua completude.

Numa percepção semelhante, Sigmund Freud já havia nomeado e descrito a sensação incomum de reconhecer-se no outro. $O$ termo alemão "unheimlich", traduzido nas versões em português como "estranho" ou "inquietante", não apenas se oporia a "heimlich", como também conteria em si próprio os diversos significados dessa palavra, que abarca desde a segurança do privado até o místico obscuro. O psicanalista define o estranho, portanto, como "aquela categoria do assustador que remete ao que é conhecido, de velho, e há muito familiar" (FREUD, 2006, p. 238). Essa caracterização do que é familiar perde a denotação de intimidade confortável e se torna uma 
ameaça ao romper os limites pré-estabelecidos e estabelecer contato com o exterior, conferindo ao indivíduo o sentimento de exposição e vulnerabilidade. Como um segredo revelado a desconhecidos, o duplo emerge do âmago do sujeito e passa a habitar o mundo, tomando seu próprio rumo e exibindo, em suas atitudes, traços que até então podem ter sido obsessivamente ocultos pelo original.

Outro termo que se aplica à situação do visconde de Calvino foi designado por Jean-Paul Richter "Doppelgänger", e é a denominação de duplo consagrada pelo Romantismo alemão ${ }^{1}$. Como explica Nicole Fernandez Bravo (2000, p. 261), "Significa literalmente 'aquele que caminha do lado', 'companheiro de estrada'. Endossamos a definição dada pelo próprio Richter: 'assim designamos as pessoas que se vêem a si mesmas'”. Mas o caso de Medardo é ainda mais complexo, pois, apesar de, frente a frente, suas partes direita e esquerda verem a si mesmas, a imagem representada no duplo é sempre espelhada. E o espelho, como já diria Clément Rosset (2008, p. 90), "é enganador e constitui uma 'falsa evidência', quer dizer, a ilusão de uma visão: ele me mostra não eu, mas um inverso, um outro; não meu corpo, mas uma superfície, um reflexo". Nos meio-viscondes, tal inversão é ainda mais evidente no âmbito psicológico, em que suas qualidades são completamente opostas.

Cabe a O Mesquinho, a metade direita, todo sentimento egoísta, frio e precisamente mau, enquanto é inerente a O Bom a complacência, a imparcialidade, o sacrifício em favor de outrem, a sensibilidade à beleza das artes e da natureza. O lado esquerdo, portanto, se deixava conduzir pelos sentimentos e tinha completa fé de que poderia convencer toda Terralba a unir-se a ele nas boas ações. $O$ amor que nutria por Pamela se confundia com o feliz sonho que tinha de, juntos, serem ainda mais úteis nos serviços prestados à sociedade. Seu duplo, pelo contrário, jamais abandonava o pensamento prático e a razão: "- Pamela, eu decidi apaixonar-me por você - disse ele" (CALVINO, 2011, p. 53, grifo nosso). Impondo a autoridade de seu título de visconde, forçava os conterrâneos a realizar tarefas cruéis. $O$ poder desmedido também se demonstrava pelo castelo em que vivia e pelas nobres roupas que usava, destoando da realidade a que pertencia.

Adilson dos Santos denomina esse tipo de representação como a do "duplo negativo", quando não há "semelhança no sentir, pensar e agir" e se apresentam "caracteres próprios diametralmente opostos" (SANTOS,

1 O Romantismo surgiu no final do século XVIII, na Alemanha. Contrapondo-se ao movimento antecessor, o Iluminismo, a escola romântica preteriu a racionalidade para se focar em temas subjetivos, como o sobrenatural, os sentimentos e o inconsciente. Jean-Paul Richter, um dos escritores envolvidos nessa corrente literária, criou o termo "Doppelgänger" para se referir a um dos personagens de seu romance humorístico Siebenkäs. 
2009, p. 71). Todavia, a tensão e o conflito que geralmente surgem nesses casos se manifestam com mais profundidade, em $O$ visconde partido ao meio, na mútua anulação de feitos entre as partes de Medardo, ao invés de em disputas diretas. Assim como nas comédias romanas de Plauto, datadas entre o terceiro e o segundo séculos a.C. e já inspiradas nos gregos, a confusão causada pela semelhança entre os meio-viscondes é artifício de humor. Inicialmente, Terralba conhecia apenas o Mesquinho, que destruía plantações, rasgava pequenos animais ao meio, sequestrava crianças e causava avalanches de pedras. Quando O Bom apareceu, realizando suas ações altruístas, levou um tempo para que a população notasse a diferença física entre eles, sendo tomada por um assombro geral enquanto pensava que aquelas atitudes tão contraditórias provinham de um único indivíduo:

Fazia tempo que a besta do visconde só golpeava as andorinhas; e não para matá-las, mas para feri-las e aleijá-las. Contudo, agora podiam ser vistas no céu andorinhas com as patas enfaixadas e amarradas com gravetos de apoio ou com as asas coladas e com curativos; havia um bando de andorinhas assim ataviadas que voavam com prudência todas juntas, feito convalescentes de um hospital de passarinhos, e inverossimilmente dizia-se que o próprio Medardo era o médico (CALVINO, 2011, p. 68).

Até o momento do duelo pela mão de Pamela, porém, ambos viviam tranquilamente em Terralba, mesmo cientes de dividirem espaço com uma figura semelhante. $O$ que mais os aproximou de um enfrentamento foi quando, ao perceber a popularidade crescente de O Bom, seu duplo mau, enciumado, ordenou aos guardas que o matassem; contudo, seu plano não foi executado, por todos admirarem e protegerem seu oponente. Como dito anteriormente, o antagonismo se manifestou apenas no clímax do enredo, provocado intencionalmente pela amada. Antes disso, nem o interesse pela mesma mulher foi capaz de acarretar um conflito físico entre os viscondes. A metade boa, em tudo generosa e caridosa, estava disposta a abdicar do amor para satisfazer seu duplo. Este, por sua vez, desenvolveu o estratagema de incentivar o casamento da moça com o rival e, mais tarde, exigir o direito de tomá-la como esposa, visto que possuíam o mesmo nome. Não partiria de nenhum lado a ousadia de se encontrar pessoalmente com o opositor.

Em certa ocasião, O Bom revelou inclusive sentir pena de O Mesquinho e não julgá-lo pelas más ações cometidas: "Eu, que sei o que significa ser metade de um homem, não posso deixar de sofrer por ele" (CALVINO, 2011, p. 70). Quando ameaçado de morte pelo rival, ao invés de incentivar a revolta que se organizava entre seus servos, fez com que desistissem de matar o visconde mau. Por fim, como sinal de paz, a metade bondosa lhes 
entregou uma ampola com as últimas gramas do unguento que aliviava as dores de sua cicatriz de guerra, para que a aflição do duplo fosse, ainda que momentaneamente, suavizada. Sua fala, nesse momento, é bastante significativa: "é o presente de alguém que sabe o que significa ter as veias que terminam numa tampa" (CALVINO, 2011, p. 83). O Bom, sendo parte de 0 Mesquinho, era o único indivíduo capaz de mensurar suas amarguras e dele se compadecer. Adilson dos Santos explica como é preciso ter conhecimento do outro como parâmetro para a construção da própria identidade:

É, pois, através da alteridade, da aceitação e percepção dos valores do outro, da identificação da diferença que ele suscita, que se realiza o processo de autocompreensão de um indivíduo e que se conduz à contínua conquista da identidade (SANTOS, 2009, p. 73).

Ao se colocar no lugar do duplo e sentir sua dor, O Bom iniciou seu percurso de conhecimento próprio. Na literatura, o duplo, principalmente o de categoria psicológica, várias vezes está relacionado à observação do próprio ser, resgatando os desejos e traumas mais interiores. Por essa razão, uma de suas primeiras denominações é alter ego (BRAVO, 2000, p. 261), termo que remete à psiquiatria: "o elemento que amedronta pode mostrar-se ser algo reprimido que retorna. [...] esse estranho não é nada novo ou alheio, porém algo que é familiar e há muito estabelecido na mente" (FREUD, 2006, p. 258). A situação de Medardo é ainda mais interessante por se tratar do caso de dois corpos e personalidades totalmente separadas, mas ainda assim pertencentes a apenas um visconde. Essa é a ilustração ideal da seguinte reflexão de Bakhtin sobre a necessidade da improvável fusão entre duas pessoas, de horizontes concretos particulares, para que se atinja uma percepção completa do indivíduo. No visconde, é possível unir a dimensão do eu, interior, à do outro, exterior:

Quando contemplo no todo um homem situado fora e diante de mim, nossos horizontes concretos efetivamente vivenciáveis não coincidem. [...] Quando nos olhamos, dois diferentes mundos se refletem na pupila dos nossos olhos. Assumindo a devida posição, é possível reduzir ao mínimo essa diferença de horizontes, mas para eliminá-la inteiramente urge fundir-se em um todo único e tornar-se uma só pessoa. (BAKHTIN, 2011, p. 21)

Ao atingir tal compreensão da dependência do outro para que se conheça o próprio interior, retornamos à ponderação de Clément Rosset sobre o reflexo. Para o filósofo, apesar de enganador, o espelho, como uma manifestação do duplo, é "a última chance de me apreender" (ROSSET, 2008, p. 90), a última pista possível no processo de autoconhecimento, o mais 
próximo que poderemos chegar de uma contemplação pessoal. "É por isso que a busca do eu, especialmente nas perturbações de desdobramento, está sempre ligada a uma espécie de retorno obstinado ao espelho e a tudo o que pode apresentar uma analogia com o espelho" (ROSSET, 2008, p. 90); analogia esta que Calvino criou perfeitamente nos meio-viscondes simétricos, como já comentamos. Até mesmo a estrutura do enredo é duplicada, alternando a narrativa entre os protagonistas partidos ao meio, complementando assim as informações a que o leitor teria acesso caso acompanhasse apenas uma das metades.

Contudo, sendo o reconhecimento de si próprio a resposta a uma inquietação que acompanha o ser humano desde o primórdio dos tempos, por que a reação do sujeito é evitar ou exterminar seu duplo? O próprio Clément Rosset aborda a questão: "O afastamento de si por si mesmo, o qual sempre acaba por confirmar o seu próprio eu, é igualmente perceptível no afastamento de outros que não si próprio, quando parece que estes são ao mesmo tempo indesejáveis e semelhantes" (ROSSET, 2008, p. 95). A introspecção também se faz necessária durante a autodescoberta, para que se visualize com clareza a fronteira entre o eu e o outro. É perturbador ao indivíduo perceber suas características no próximo e concluir não ser tão precisa quanto imaginava a delimitação dessa fronteira, pois então deve admitir não ser único, nem merecer destaque entre os demais. Essa experiência pode ser desagradável até quando a semelhança é perceptível apenas ao sujeito, que vê manifestado em seu duplo o que reprime em si mesmo - é a configuração de estranho de que Freud discorre.

Para o teórico György Lukács (2000), uma outra problemática do ser desenvolveu-se no advento da Idade Moderna, época em que as respostas da mitologia e da religião deixaram de ser satisfatórias ao ser humano. As dúvidas se intensificaram com a profusão de segmentos filosóficos, psicológicos, científicos e tecnológicos no século XX, que exigiam do sujeito uma tomada de posição, ainda que constantemente a refutassem. Nesse contexto, o indivíduo se desdobrou entre o "ideal do dever-ser", o papel de perfeição interpretado perante a sociedade, e a "realidade do ser", sua essência reprimida. É o que vemos em Medardo, dividido entre uma parte boa e dedicada ao próximo, detentora de qualidades louváveis a qualquer público, e outra egoísta e dominadora, a representação de todas as características desprezíveis que permanecem ocultas sempre que possível.

Para a surpresa do leitor, sequer a metade boa conseguiu ser bem acolhida na sociedade, reconstituindo a imagem do herói problemático de Lukács, deslocado a despeito de seus esforços (LUKÁCS, 2000, p. 79-80). 0 Bom não se contentava em apenas prestar serviços aos moradores de Terralba, mas estava disposto a tornar a prática do bem comum entre eles. Ele 
exigia de Pamela uma abnegação como a sua e entendia que somente desse modo seriam felizes: “- Fazer boas ações juntos é a única maneira de nos amarmos" (CALVINO, 2011, p. 71). Quanto aos demais, dedicava o tempo a ensinar-lhes os valores morais, a avaliá-los e repreendê-los pelas faltas, tornando a vida daquelas pessoas ainda mais exaustiva e restrita: "Com aquela exígua figura rígida numa perna só, vestida de negro, cerimoniosa e distribuindo regras, ninguém podia fazer o que lhe apetecia sem ser recriminado em praça pública, suscitando malignidade e despeito" (CALVINO, 2011, p. 85-86). Todos passaram a detestá-lo e, ironicamente, por vezes considerá-lo ainda pior que $\mathrm{O}$ Mesquinho.

$\mathrm{O}$ assunto foi abordado por Italo Calvino em uma entrevista aos estudantes de Pesaro, cujos trechos foram transcritos na apresentação de $O$ visconde partido ao meio: "que estas duas metades, a boa e a má, fossem da mesma forma insuportáveis era um efeito cômico e ao mesmo tempo também significativo, porque às vezes os bons, as pessoas demasiado programaticamente boas e cheias de boas intenções, são uns chatos terríveis" (CALVINO, 2011, p. 6). Ao expurgar de si toda a maldade, O Bom perdeu, junto com os defeitos, a humanidade. Dessa forma, jamais poderia esperar que um lugar lhe fosse reservado junto às demais pessoas, que, além de tudo, se sentiam julgadas por ele. Compreendendo sua condição, podemos notar em sua própria alcunha certo tom de ironia, como se a qualidade de "bom" não lhe fosse atribuída senão por si próprio.

Nessa mesma entrevista, Calvino revelou o que o motivou a criar Medardo: "pensei que o tema do homem cortado em dois, do homem partido ao meio fosse um tema significativo, tivesse um significado contemporâneo: todos nos sentimos de algum modo incompletos, todos realizamos uma parte de nós mesmos e não a outra" (CALVINO, 2011, p. 5). Assim como Lukács e tantos outros teóricos, o autor entendia que a busca por uma identidade única e particular é própria de todo ser humano e, conhecedor como era da literatura fantástica, fez uso dela de maneira apurada para tratar dessa questão. $O$ visconde partido ao meio nos remete a muitos autores renomados, como Robert Louis Stevenson, autor de The Strange case of Dr. Jekyll and Mr. Hyde, a quem o próprio Italo Calvino se refere (CALVINO, 2011, p. 6). Mas o diálogo mais evidentemente estabelecido é com Die Elixiere des Teufels, de E. T. A. Hoffmann.

Na novela, traduzida para o português como os elixires do diabo, o duplo se constitui por meio do pai desconhecido que aparece em sonhos, representação da consciência, e também pelo meio-irmão Victor, que revela o lado instintivo e propenso à loucura do protagonista. Este, assim como o visconde de Calvino, se chama Medardo e vive o conflito de não compreender as forças contraditórias que habitam seu ser. Por sua condição de monge 
capuchinho, procura abstrair-se dos desejos terrenos e purificar-se; contudo, por ter sido concebido num ato herege, carrega o fardo do impulso sensual, homicida e insano. Explica Nicole Fernandez Bravo (2000, p. 273): "Duas tendências se combatem em Medardo: de um lado, a aspiração ao bem, que [...] o faz 'renascer', para escolher a vida mansa e retirada de um convento; de outro, a busca da satisfação imediata dos desejos profanadores". Apesar da semelhança com o personagem do autor italiano, ao Medardo de Hoffmann é reservado um destino muito mais dramático, preso por seus crimes e perdido numa risada histérica.

$\mathrm{Na}$ história de Calvino, entretanto, é a morte que arremata as transições do personagem, nem por isso imprimindo ao enredo um ar trágico. Em seu estudo sobre o duplo, Otto Rank conta que, desde os tempos antigos, o tema, relacionado às figuras da sombra e do reflexo, deixou gradualmente de ser visto como espírito protetor e se tornou presságio de males e perseguições. No caso de Medardo, porém, a concepção de resguardo foi retomada. Foi graças à insólita duplicação que ele sobreviveu ao tiro certeiro de canhão e pôde se recuperar brevemente. Ao fim, quando as metades duelaram entre si, o ferimento sofrido por cada uma lhes conferiu uma nova chance, um restabelecimento para se recomeçar. Geralmente, "a vida do duplo está intimamente ligada à da própria pessoa" (RANK, 2013, p. 32) e, por essa razão, não se pode fugir dele, pois, matando-o, o indivíduo atinge a si mesmo. Mas o visconde soluciona esse paradoxo da morte, demonstrando que as más experiências, quando bem trabalhadas, podem resultar em crescimento e completude.

\section{CONSIDERAções Finais}

Calvino costura em seu personagem diversas das formas duplas que surgiram ao longo da história da literatura. Apesar da bipartição de Medardo se manifestar fisicamente, como um elemento insólito do livro, trata-se de uma duplicidade interior, por se originar do psicológico do indivíduo. Todavia, pares formados a partir de uma mesma personalidade geralmente fazem uso de pinturas, retratos ou reflexos como representação do semelhante, sem que o conflito se exteriorize em outro personagem, como no caso dos meio-viscondes. Moralmente opostos, outra característica de 0 Bom e O Mesquinho é serem duplos negativos, que sempre anulam as recíprocas ações um do outro. Nesse sentido se retoma o humor das comédias gregas e romanas da Antiguidade, que partiam da confusão causada pela semelhança física entre gêmeos para gerar o riso.

$O$ visconde de Calvino também foi concebido com traços originais. A morte é o ponto de partida da sua bipartição, assim como a solução do 
enredo. Nas duas ocasiões, do ferimento surge a vida, do problema vem o crescimento do personagem. Outro fato é que não há matriz e cópia entre os duplos, por serem ambos parte de Medardo, surgidos no mesmo instante. Por todo o enredo, jamais um se sobrepõe ao outro. Até mesmo na batalha final não há vencedor, sendo os dois lesionados e socorridos. Por fim, ao serem novamente unidos, protagonizam um final feliz, demonstrando ser possível um desenlace que favoreça ambas as partes.

\section{REFERÊNCIAS}

BAKHTIN, M. Estética da criação verbal. Tradução de Paulo Bezerra. 6 ed. São Paulo: WMF Martins Fontes, 2011.

BRAVO, N. F. Duplo. In: BRUNEL, P. (dir.). Dicionário de mitos literários. Tradução de Carlos Sussekind et al. 3. ed. Rio de Janeiro: José Olympio, 2000.

CALVINO, I. O visconde partido ao meio. Tradução de Nilson Moulin. São Paulo: Companhia das Letras, 2011.

FREUD, S. O "estranho". In: FREUD, S. História de uma neurose infantil e outros trabalhos (1917-1919). Rio de Janeiro: Imago, 2006.

LUKÁCS, G. A teoria do romance. Tradução de José Marcos Mariani de Macedo. São Paulo: Duas Cidades/ Editora 34, 2000.

RANK, O. O duplo. Porto Alegre: Dublinensem, 2013.

ROSSET, C. A ilusão psicológica: o homem e seu duplo. In: ROSSET, C. O real e seu duplo: ensaio sobre a ilusão. Tradução de José Thomaz Brum. Rio de Janeiro: José Olympio, 2008. (Sabor Literário).

SANTOS, A. Um périplo pelo território duplo. Revista investigações, Recife, v. 22, n. 1, p. 51101, jan. 2009.

Submetido em: 08/07/2015

Aceito em: 17/10/2015

Revista Letras, Curitiba, N. 92 p. 38-48, JUL/DEZ. 2015.

ISSN 2236-0999 (VERSÃo ELETRÔNICA) 